\title{
RESPECT Project of America and Its Inspiration to Excellent Teachers Cultivating Plan of China
}

\author{
J.H. Liang, Bo Wang \\ College of Early Childhood and Special Education, Weifang, Shandong, China
}

\begin{abstract}
In order to attract, retain and reward outstanding teachers, improve the quality of education, and show the new vision for current teaching and leadership in America, the U.S. Department of Education started to invested $\$ 5$ billion in the RESPECT Project in February 2012, and formally announced the Blueprint for RESPECT in April 2013. The making process, core idea and supporting measures of RESPECT Project have important implications for the Excellent Teachers Cultivating Plan in China.
\end{abstract}

Keywords—RESPECT Project; Excellent Teachers Cultivating Plan

\section{美国《RESPECT 工程》对我国卓越教师培养计划的启$$
\text { 示 }
$$$$
\text { 梁纪恒 王波 }
$$ \\ 滩坊学院幼教特教师范学院, 潍坊, 山东, 中国}

摘 要 为吸引、留住和奖励优秀教师, 提高教育质量, 展示当前美国教学和领导的新愿景, 2012 年 2 月, 美国教育部启动了斥 资 50 亿美元的 RESPECT 工程, 并于 2013 年 4 月正式公布了 RESPECT 工程蓝图。美国 RESPECT 工程提出的背景、出台过程、核心 理念及配套措施等，对我国正在实施的卓越教师培养计划具有重要的启示意义。

关键词 RESPECT 工程, 卓越教师培养计划

为吸引、留住和奖励优秀教师, 提高教育质量, 展示 当前美国教学和领导的新愿景, 2012 年 2 月, 美国教育部 启动了一项斥资 50 亿美元的 RESPECT 工程(RESPECT Project), RESPECT 的全称是《追求教育成功、专业卓越及 合作教学》(Recognizing Educational Success, Professional Excellence and Collaborative Teaching, 简称 RESPECT)。 2013 年 4 月美国正式公布了奥巴马政府的 RESPECT 工程 蓝图 (Blueprint for RESPECT)。美国 RESPECT 工程提出 的背景、出台过程、核心理念和配套措施等, 对我国正在实 施的卓越教师培养计划具有重要的启示。

\section{RESPECT 工程提出的背景与过程}

美国是当今世界公认的经济强国, 这得益于历届政府 对教育的重视和国家对未来的忧患意识。早在上世纪 80 年
代, 美国就认识到当时经济发展问题的主要根源在于教育 失败, 经济发展的不景气直接刺激了政府对教育进行改革 干预的决心, 并相继颁布和出台了《国家在危机中: 教育 改革势在必行》、《美国 2000 年教育战略》(America 2000: An Education Strategy) 和《不让一个孩子掉队》法案 (No child Left Behind, NCLB)等政策报告和法律法规。在一项关于国 家所面临最重要议题的公众调查中, 80 年代时期, 教育仅 仅位列 51 个议题的第 23 位, 到 2000 年时, 教育则成为国 家面临的最重要议题[1]。RESPECT 工程的提出就与对教师 职业的忧虑、对国民教育的反思、以及对学生所面临国际 挑战的担忧等密切相关。

\section{1 对教师职业的忧虑}

目前, 美国各界已充分认识到, 为让年轻人更好地应 
对日益激烈的全球竞争, 必须建立一支高素质的稳定的教 师队伍, 确保教师职业受到高度尊重并获得充分支持。由 于有些教师缺少支持, 感觉学校文化中缺乏弹性的工作规 则, 阻碍创新并限制他们的合作机会, 结果导致很多优秀 的大学毕业生从未考虑进入教师职业, 而那些在职教师也 面临着走留两难的纠结。而随着大批教师逐渐退休, 目前 美国教师的供需问题更是成为关注的焦点。过去 10 年里, 公立学校的入学率一直保持稳定, 预计从 2010-2011 学年 到 2021-2022 学年, 仅公立学校中小学生就保持 7\%的年增 长率, 数量从 4950 万增加到 5310 万[2]。因此, 保证一支 数量充足的稳定教师队伍成为地方、各州和联邦政府的重 要政策议题。

\section{2 对国民教育的反思}

自 2002 年美国总统布什签署《不让一个孩子掉队》法 案 (NCLB) 以来, 美国追求教育公平、强化绩效问责制等 理念已经深深融入到学校系统文化之中。但是, 《不让一个 孩子掉队》并没有缩小成绩差距, 有色人种学生和贫困学 生的教育需要也没有得到充分满足。统计显示, 仅 $78 \%$ 的 学生能够在在四年内完成高中学业, 而非裔美国人和拉丁 美洲人的这一比例仅仅为 $66 \%$ 和 $71 \%$ 。特别是当前, 美国 超过 $60 \%$ 的工作需要有高等教育背景, 这就意味着接近四 分之一的年轻人达不到就业竞争的最低门槛。而那些学业 成就持续低下的儿童, 获得成功的可能性更加渺茫[3]。另 外, 目前美国初中和高中学校里普遍存在滥用停学处分的 现象也引起了社会的关注, 仅仅在 2009-2010 学年, 美国 所调查的 2.6 万所中学里就有超过 200 万名学生受到过停 学处分, 这意味着每九名学生中就有一名学生在该学年受 到过一次以上的停学处分 [4]。

\section{3 对学生所面临国际挑战的担忧}

当前, 以知识为基础的全球就业市场竞争日益加剧, 然而对学生成绩的国际评估中, 美国学生却表现平平。早 在 1983 年, 美国发表的题为《国家在危机中: 教育改革势 在必行》的报告就提到, 在与其他工业国家学生 19 次测验 成绩的国际比较中, 美国学生从未进入第一或第二档次, 甚至有 7 次位居末档; 在多数的标准化测验中, 高中学生 的平均分数甚至低于 26 年前的测验分 [5]。而作为全球化背 景下基础教育质量多元评价体系中的一项重要指标, 国际 学生评估项目 (Program for International Student Assessment, PISA) 2012 年的最新数据显示, 在对 34 个经济合作与发 展组织 (OECD) 成员国 15 岁学生的比较中, 美国学生阅 读排名第 17 , 在科学项目中排名第 21 , 在数学项目上则排
名第 26[6]。

为改变当前教育的现状, 奥巴马政府提出了教育优先 的施政理念并将促进学校发展作为国策。同时, 全美学者 和专业组织也都呼吁启动一系列革新性的、全方位的教师 专业提升和改造方案。尤其是, 一些全国性组织为促进教 师职业而提出了共同的愿景, 包括美国学校管理者协会 (AASA)、美国教师联合会 (AFT)、美国州立学校首席官 员委员会 (CCSSO)、大城市学校委员会 (CGCS)、美国联 邦仲裁与调解局 (MCS)、全美教育协会 (NEA)、全美学 校董事会协会 (NSBA) 等。随着全国性权威组织所达成的 共识渐趋增多, 受此启发, 同时为呼应教师和学校领导者 的倡议, 美国教育部开始致力于开发一套提升和改造教师 职业的政策框架。在制定这一框架过程中，教育部对相关 文献进行了回顾, 与各级教育管理者开展合作性对话。教 育部与合作者召开了一系列协调会以明确各种共识, 并鼓 励精诚合作, 其中包括两次史无前例的会议: 2011 年 2 月 的劳资合作会议 ( labor-management collaboration conferences）以及 2011 年 3 月召开的教师职业国际峰会 (International Summit on the Teaching Profession)。同时, 教育部通过发起全国性教师职业会议以及召开由教师与领 导者参加的圆桌会议, 千方百计地寻求教育者的直接参与。

为帮助搭建全国性对话的框架, 并促成对未来政策的 了解, 教育部勾画了教学、领导和学习的新蓝图。在起草 勾画蓝图过程中, 吸纳地方、州、国家和国际教育者和专 业组织的参与, 对教师职业进行了深层次的探讨。2011 年 夏天开始, 教育部的教学大使 (Teaching Ambassador Fellows) 深入到各地的学校、学区和教师网络, 与不同学 科的教师、以及不用职位和不同经验水平的教师, 围绕一 项名为《面向 21 世纪的教师职业》(A Teaching Profession for the 21st Century) 的框架草案, 就有关教学的新愿景进行讨 论。2011 年晚秋和初冬前后, 教师对前期达成的关于教师 职业愿景的意见建议进行了更深入细致的研讨 [7]。

2012 年 2 月, 美国教育部长邓肯宣布正式启动 RESPECT 工程, 围绕教师职业进行全国对话, 邀请教师、 校长等教育者通过网络等途径献计献策。2012 年 5 月, 美 国教育部联合美国学校管理者协会 (AASA)、美国教师联 合会 (AFT)、美国州立学校首席官员委员会 (CCSSO) 等, 在俄亥俄州的辛辛那提共同承办了第二届劳资合作会议, 召集学区和州领导集中精力, 通力协作以推进教师职业革 新。在会议准备过程中, 相关合作组织对改革教师职业提 出来各自的最佳建议, 各组织和教育专家的筬言建议直接 促成了 RESPECT 工程的提出。最后, 各专业组织代表教 师、主管、学校董事会以及州领导等共同起草了一份《共 同愿景: 革新教师职业》(Shared Vision: Transforming the 
Teaching Profession), 这项史无前例的共同愿景成为 RESPECT 工程政策框架的主要内容。从 2012 年底开始, 教育部的教学大使继续与教育者和相关利益者就 RESPECT 工程进行更大规模的全国性对话会谈。截至 2013 年 2 月, RESPECT 工程已通过在美国各地的 360 多场圆桌 会议, 召集了 5700 多名教育工作者进行对话[8]。2013 年 4 月, 美国教育部正式公布了奥巴马政府的 RESPECT 工程 蓝图。

\section{RESPECT 工程的主要内容}

RESPECT 工程政策框架由七大核心要素组成: 共同责 任与领导 (shared responsibility and leadership)、招聘与准 备 (recruitment and preparation)、成长与发展 (growth and development)、评价 (evaluation)、薪酬与晋升 (compensation and advancement)、学校氛围 (school climate)、社区参与 (community engagement)。教育者一致认为这些要素是教 师职业革新的关键, 同时也是国内外最高绩效学校体系 (highest-performing school systems) 的特质[9]。

\section{(1)共同担责与领导的文化（Culture of Shared} Responsibility and Leadership )

在新型教师专业中, 教育者对学生的学习共同担责。 共同决策的体系和开放实践为教育者进行最佳教学提供了 协作自主权，教师职业也承担着满足高标准实践的责任。 在专业文化理念下, 教师和校长协力对教师选择、分派、 评价、解雇和晋升等进行决策, 并将学生学习作为决策的 重中之重。

(2) 顶尖人才, 为成功做准备 (Top Talent, Prepared for Success)

高效能教师教授的学生学业成就更高, 有更高的毕业 率和大学维持率, 公民参与度更高, 并且有更高的终生收 入。因此, 应将吸纳高水平的优秀人才进入教师和校长队 伍, 作为优先考虑的议题, 不管他们是新毕业的还是经过 职业转换的, 也不论他们通过传统或选择性途径进入教师 行业; 为那些培养高效能教育者、设置高质量的实质性课 程和临床实践的教育项目提供支持; 推广最成功的的教育 项目, 促进其他项目进行改善, 同时停办那些受到支持后 仍然表现最低效的项目; 准备工作应包括重要的临床机会, 通过高效能的教师或校长对有抱负的教育者进行监督、指 导和评估 (最好是在候选人将最终工作的学校环境中)。此 外, 有抱负的教育者必须满足进入教师行业的高门槛, 掌 握各种教学策略并恰如其分地使用; 具备与学生与同事有 效地开展工作的性向与态度; 知道如何有目的地计划、分
析学生学业成就, 能反思自己的实践, 并根据需要进行调 整。

(3)持续成长与专业发展 (Continuous Growth and Professional Development)

有效能的教师和校长在其职业生涯中应持续学习。有 效能的学校和学区都是学习社区, 在这里教师和校长以独 立或与合作方式不断反思和改进实践。当利用结构化的时 间进行协同工作，专业实践社区会茁壮成长。从初任教师 的入职引导, 到最优秀教师的实践传播, 专业发展是提升 的关键, 应全力促进专业发展。

(4)有效能的教师与校长 (Effective Teachers and Principals)

有效能的教育工作者需要有高标准的专业实践, 具备 提高学生学习的能力。因此, 效能的评估必须根据对学生 学业成长的测量、来自课堂上和学校的实践证据、以及对 同事和学校社区的贡献。评估结果应能指导专业支持和发 展, 并有助于人事决策, 例如对教师和校长的委派、专业 地位的认定、领导职务的晋升、以及对受到支持依然效能 低下的教育者的解雇。良好的评价系统应该提供来自同事 和上司的反馈, 并且反馈应当有意义、可靠、及时和具有 可操作性, 另外, 良好的评价系统使用证据本位的公正、 准确而透明的过程。

\section{(5)具有竞争性薪酬的职业生涯(Professional Career} Continuum With Competitive Compensation)

招聘和留任高质量人才进入教师队伍是保证教育成功 的重要举措。为实现这一点, 需要给教育者提供有机会担 任越来越负责任角色的职业路径。这些角色离不开足够高 的薪酬, 以吸引和留住高技能劳动力、反映效能、专业知 识和每个教育工作者的贡献, 并与类似行业理应获得的的 社会尊重相吻合。

(6) 成功教学的条件 (Conditions for Successful Teaching and Learning )

高功能系统能够增强教育工作者的成就, 而功能缺位 的学校或学区甚至能削弱优秀老师的影响。学校与学区的 氛围和文化、时间利用、编制方法、技术使用、支持服务 的部署, 以及家庭和社区的参与等应进行优化, 以不断提 高学生的成就。此外, 必须准备好为最具需求的学生 (包 括低收入家庭的学生、少数民族学生、英语学习者和残疾 学生）配备最好的教师和校长, 并确保所有学生有机会获 得其他必要资源（如技术、指导材料、以及社会、健康和 营养服务), 以助推他们的学业成功。 


\section{(7) 社区参与（Engaged Communities）}

只有儿童安全健康、营养良好并且受过良好教育, 一 个社区才能够蓬勃发展。社区缺乏对学生成就的责任, 学 校也就不会成为繁荣社区的有力支柱。因此, 认识到社区 和学校的命运有着千丝万缕的联系, 必须努力使教育工作 者将社区资源、专业知识和活动进行有机结合, 让社区为 有效能的学校保驾护航。

\section{3. 促成 RESPECT 工程实施的支持保障举措}

尊师工程的七大核心要素相互联系,共同影响工程的 成功实施。为促进尊师工程的顺利实施, 充分发挥其提升 和改造教师专业的效能, 美国政府和教育部围绕七大核心 要素实施了一系列政策法规，并提供了雄厚的资金支持。 例如, 为解决教师短缺和离职率高的问题, 早在 2009 年, 美国教育部就开始启动了一项“教学运动”（TEACH campaign), 致力于将教师职业纳入优秀高校毕业生的职业 选择。奥巴马总统甚至亲自为此参与制作了一则公益宣传 广告 (public service announcement, PSA), 力挺“教学运 动”[10]; 考虑到科学、技术、工程和数学 ( science, technology, engineering, and mathematics, STEM)专业受到就业市场的 青崃、薪酬高, 并且关系到国家竞争力, 奥巴马总统要求 在未来 10 年内招聘、准备和留任 10 万名优秀的 STEM 专 业教师, 高等院校要向社会培养 100 万名 STEM 专业毕业 生, 包括西班牙裔, 非裔美国人、妇女、残疾人等。另外, 美国还专门组建了 STEM 教育委员会 (Committee on STEM Education, CoSTEM), 包括所有重要科学机构和教育部等 13 个合作部门[11]。

为培养高效能的教师和校长队伍, 2009 年以来, 美国 教育部实施的《ESEA 法案修正提案》、《力争上游》(Race to the Top ,RTT) 计划 、《教师奖励基金》(Teacher Incentive Fund, TIF)等一系列政策法规和倡议, 从不同角度要求构 建对教师和领导的支持和评估体系。其中《教师奖励基金》 特别注重通过提高教师效能来提高学生成就, 致力于在高 需求学校 (high-need school) 针对教师和校长实施绩效薪 酬制度 (performance-based compensation systems), 增加高 效能教师的数量, 为贫穷学生、少数民族学生和来自人员 配备艰难地区的处境不利学生进行授课 [12]。

为塑造成功教学的条件, 美国政府更是繁费苦心。美 国各州利用充分利用学校提升赞助金 (SIG) 提供的资金来 扶持薄弱学校的转型和变革。另外, 2012 年 8 月, 美国教 育部正式公布了《 2012 力争上游学区竞争计划》(2012 Race to the Top-District competition, RTT-D), 该计划将提供 4 亿美元经费作为各学区竞争性补助经费, 针对学区层级的
教育改革进行竞争性经费补助, 加强学区的课堂教学实 务, 以确保每一个学生都能接受到良好的教学与服务。

《力争上游学区竞争计划》主要目的在鼓励学区构建以课 堂为单位的改革计划、促进学习、提高学业成就和教师教 育成效、降低学生成就差距, 同时, 强化每一个学生大学 与就业准备度。2013 年, 共有阿肯色州的斯普林代尔学区 等 5 个学区成功申请第二轮《力争上游学区竞争计划》, 共获得 1.2 亿美元的资助[13]。

\section{RESPECT 工程对我国实施卓越教师培养计划的启 示}

2014 年 8 月, 教育部印发了《关于实施卓越教师培养 计划的意见》, 旨在以实施卓越教师培养计划为抓手, 推动 师范院校深化教师培养机制、课程、教学、师资、质量评 价等方面的综合改革, 努力培养一大批有理想信念、有道 德情操、有扎实学识、有仁爱之心的好教师。作为提升和 改造教师职业的一项举措, RESPECT 工程体现了美国致力 于塑造高素质的、薪资优厚、并受人尊敬的教师职业的国 家理念, RESPECT 工程对我国实施卓越教师培养计划具有 重要的启示。

首先, 加快教育法制建设, 制定和完善相关教育法律 法规。我国应根据国情和教育改革发展需要, 建立督促制 定相关法律配套法规的工作机制。特别是一些行政法规和 地方性法规作为我国教育法律体系的重要组成部分, 是对 法律的细化和补充, 为更好保障法律的有效实施, 在新制 定和修改相关法律时, 努力做到其配套法规要与法律草案 同步起草。

其次, 加大对教师教育的投入力度。教育投入是支撑 国家长远发展的基础性、战略性投资, 是教育事业的物质 基础, 是公共财政保障的重点。国家要充分认识加大财政 教育投入的重要性和紧迫性，健全以政府投入为主、多渠 道筹集教育经费的体制, 大幅度增加教育投入。特别是要 合理安排使用财政教育经费, 全面推进教育经费的科学化 精细化管理, 切实提高资金使用效益。同时, 还要优化教 育投入结构, 注重教育均衡。在政策制定、薪酬及配套的 激励措施方面，向农村地区、边远地区、贫困地区和民族 地区以及学校、师资短缺学科倾斜, 并为低收入家庭、少 数民族、残障等有特殊需要的学生配置优秀教师和校长。 再次, 大力营造尊师重教的社会氛围。教师是立教之本、 兴教之源。尊师重教是重视教育的必然要求，是社会文明 进步的重要标志, 是尊重劳动、尊重知识、尊重人才、尊 重创造的具体体现。《国家中长期教育改革和发展规划纲要 (2010-2020 年)》中就指出, 有好的教师, 才有好的教育。 提高教师地位, 维护教师权益, 改善教师待遇, 使教师成 
为受人尊重的职业。当前形势下, 我们更应注重在全社会 培育良好的教育生态环境, 大力营造尊师重教的良好风尚 与负责任的育人环境, 并将尊师重教的社会风尚等相关举 措切切实实地落到实处。

第四, 吸引最优秀的人才进入教师队伍。既要提高教 师职业门槛，招聘高素质的、知识和技能水平高的毕业生， 还要加强对教师实践能力的培养, 提升他们的课堂掌控能 力和因材施教能力。另外还应拓宽教师引进路径, 吸收其 他行业优秀人员成为教师。同时, 为吸引和留住优秀人才 长期从教、终身从教, 还必须不断改善教师的工作、学习 和生活条件, 逐步提高教师的工资水平, 使得教师的工资 和其他行业比起来更有竞争力。目前, 我国有些地区通过 设立“特岗”职位、建立城乡轮岗和定期支教制度、以及实 施工资鼓励和特殊津贴政策等措施, 鼓励优秀教师到贫困 地区任教, 取得了较好的效果。

\section{参考文献(References)}

[1] McGuinn P J. No Child Left Behind and the Transformation of Federal Education Policy (1965-2005). Lawrence: University Press of Kansas, 2006.

[2] Aud S, Huaaar W, Johnson F, et al. The Condition of Education 2012(NCES 2012-045).National Center for Education Statistics, Institute of Education Sciences, U.S. Department of Education. Washington, DC. http://nces.ed.gov/pubs2012/2012045.pdf

[3] U.S. Department of Education. A Blueprint for RESPECT. http://www2.ed.gov/documents/respect/blueprint-for-respect.pd $\mathrm{f}$

[4] Losen D J, Martinez T E. Out of School and Off Track: The
Overuse of Suspensions in American Middle and High Schools. The Center for Civil Rights Remedies, The Civil Rights Project, University of California, Los Angeles, 2013. 1.

[5] National Commission on Excellence in Education. A nation at risk: A report to the nation and the Secretary of Education. Washington, DC: US Department of Education, 1983.5-6.

[6] Program for International Student Assessment（PISA）.Results from PISA 2012.

[7] http://www.oecd.org/pisa/keyfindings/PISA-2012-results-US.pd f

[8] U.S. Department of Education. Tracing the Path of RESPECT Conversations.

[9] http://www.ed.gov/teaching/respect-conversations

[10] U.S. Department of Education. President Obama Highlights Favorite Teacher in 'Teach' Campaign PSA. https://www.ed.gov/category/keyword/teach-campaign

[11] U.S. Department of Education. Science, Technology, Engineering and Math: Education for Global Leadership. http://www.ed.gov/stem

[12] U.S. Department of Education. Teacher Incentive Fund. http://www2.ed.gov/programs/teacherincentive/index.html

[13] U.S. Department of Education Names Five Winners of $\$ 120$ Million from Race to the Top-District Grant Competition. https://www2.ed.gov/programs/racetothetop-district/awards.htm 1 